\title{
THERMAL BEHAVIOUR KINETIC MODELING OF CAPSICUM ANNUUM WASTE BIOMASS USING AN ISO-CONVERSION METHOD
}

\author{
Vijetha Ponnam ${ }^{1, *}$, Praveen Ghodke ${ }^{2}$ Subbaiah Tondepu ${ }^{1}$, Ramesh Naidu Mandapati ${ }^{1}$
}

\begin{abstract}
In the present study, the pyrolysis behaviour of Capsicum Annuum stem Waste (CAW) was studied applying thermogravimetric analysis to evaluate the intrinsic kinetic parameters to develop a pyrolysis reactor for utilizing CAW. The thermal decomposition of CAW was achieved between $373-1173 \mathrm{~K}$ under inert conditions at different heating rates of 10,20 , and $30 \mathrm{~K} \mathrm{~min}^{-1}$. Model-free kinetic methods like KissingerAkahira-Sunose (KAS), Ozawa Flynn Wall (OFW) and Coats Redfern methods were applied to work out the kinetic parameters. To identify the utility of CAW and its biochar, physio-chemical characteristics such as proximate and ultimate analysis, scanning electron microscopy, and Fourier Transform Infrared analysis are reported.
\end{abstract}

Keywords: Capsicum Annuum, Thermogravimetric Analysis, Kissinger-Akahira-Sunose (KAS), Ozawa Flynn Wall (OFW), Coats Redfern Method.

\section{INTRODUCTION}

Biomass is exemplified as bio-debris coming from all kinds of vegetation or plantation. Various biomass resources are available in India in different forms. The biomass derivatives (e.g., methane, ethanol, char, and bio-oil) and the biomass itself releases $\mathrm{CO}_{2}$ when applied as a fuel but during its growth while photosynthetic process it absorbs back [1,7]. Nevertheless, biomass shared up to $14 \%$ of global primary energy need, it is not unconditionally utilized under its minor adaptation to energy [6,28]. In India, Capsicum Annuum (CA) is widely cultivated with an annual production of around 1.2 million tonnes, which contributes to about $27.24 \%$ of the total spice cultivation area and $25.65 \%$ of spice production in India [13,24]. According to Ministry of Agriculture (Department of Agriculture \& Cooperation), capsicum annuum production in India is 7.5 lakhs hectares, which leads to the generation of 52.5 lakhs tonnes of waste.

Pyrolysis is an assuring technology for biochar and bio-oil production. Bio-oil can be enhanced to light hydrocarbons with fewer aromatics and sulfur correlated to petroleum-based fuels. Biochar is a carbon-immense product obtained from the pyrolysis of sustainable raw materials and is widely used as a soil amendment in agriculture [22]. By the thermal decomposition of biomass wastes, biochar is produced [10]. Expertise on the kinetics of lignocellulosic decomposition is necessary to design various pyrolysis units. Even at high temperatures during pyrolysis there is no reaction with, water, oxygen and other reagents. Pyrolysis is the harbinger for all thermochemical methods $(11,7)$. The main constituents of biomass are cellulose, hemicelluloses, and lignin by weight percent and these proportions may vary depending on the type of biomass $[5,21]$. Previous studies have explored the thermal behavior of various biomass materials and their degradation temperatures $[16,19]$. Before the conversion of biomass to fuel, its kinetic analysis should be performed which provides the information related to the optimization of process parameters and pyrolysis reactors designing $[26,4,7]$. Due to differing composition, Individual feedstocks exhibit distinct thermal behavior profiles. Previous studies[2,23,16,27] have reported the thermal behaviour of coir pith, bagasse, casuarinas leaves and groundnut shell which shows contrasting individual deterioration temperatures. Besides, it caters to solving mathematical modeling. Kinetic behavioral variables include an order of reaction (n), frequency factor (A) and activation energy (Ea) which can be regulated by using thermogravimetric (TGA) analysis. The first attempt to analyze the kinetic behavior of Capsicum Annuum Waste (CAW) was made in this study, in spite of many other reports on

This paper was recommended for publication in revised form by Regional Editor N. Filiz Özdil

${ }^{1}$ Department of Chemical Engineering, Vignan's foundation for science technology and research, Vadlamudi, 522213, Andhra Pradesh, India.522213

${ }^{2}$ Department of Chemical Engineering, School of Engineering, University of Petroleum and Energy Studies (UPES), Dehradun, Uttarakhand 248007, India.

${ }^{*} E$-mail address: vijetha.ponnam@gmail.com

Orcid id: 0000-0003-3746-9948, 0000-0003-3427-7481, 0000-0001-6688-2710,0000-0001-5870-3938

Manuscript Received 6 June 2020, Accepted 19 October 2020 
other materials. The present study aims to know about the physicochemical characteristics and heat deterioration behavior (kinetic analysis) of CAW at heating rates of 10,20 and $30 \mathrm{~K} \mathrm{~min}^{-1}$ whose data is not available in the past to validate it as a source for thermo-chemical method.

TGA studies can be accomplished in both isothermal and non-isothermal conditions. Non-isothermal experiments are preferred over the isothermal experiments due to its less error. Non-isothermal data is widely used for determining kinetic parameters as they can be fitted to different methods. These methods are more predictable and rapid. There are definite methods accessible for interpreting the TGA report. Three model-free methods such as Kissinger-Akahira-Sunose (KAS), Ozawa Flynn Wall (OFW) and Coats Redfern method was applied to work out the kinetic parameters. Since this method doesn't require any assumption, they provide accurate values for activation energy. The data obtained from TGA analysis can be interpreted to calculate kinetic parameters of CAW.

\section{MATERIALS AND METHODS Materials}

CAW were gathered from the nearby fields in the Guntur region of Andhra Pradesh. CAW was thoroughly washed with distilled water, sun-dried, crushed into the desired size of less than $1 \mathrm{~mm}$ pieces and sealed in an airtight container to avoid moisture absorption.

\section{Methods}

\section{Proximate and ultimate analysis}

Proximate analysis for CAW was determined according to ASTM D 1762-84 standard method. Moisture content, volatile matter, ash content and fixed carbon of both biomass and Biochar were investigated. The ultimate analysis was done using Elemental (C, H, N, S) Analyser (True spec micro CHNS 209-190, LECO Corporation, USA.

\section{TG/DTG/DSC Analysis}

The thermal stability of CAW of pyrolysis reaction was analysed in triplicate using a simultaneous thermal analyser (STA 7200, Hitachi HTG, Japan) under an inert atmosphere. CAW sample of $8 \mathrm{mg}$ was taken in an aluminum crucible with a nitrogen flow rate at $30 \mathrm{~mL} \mathrm{~min}^{-1}$ within 375 to $1170 \mathrm{~K}$. Loss in the weight of biomass with temperature and time were noted. Differential Scanning Calorimetry (DSC) of CAW biomass was carried out using EX STAR DSC 7020, Hitachi HTG, Japan at three distinct heating rates of 10, 20 and $30 \mathrm{~K}$ $\mathrm{min}^{-1}$. In this study, the energy flow of CAW was reported against temperature.

\section{SEM Analysis}

The structural surface of the CAW was examined using a scanning electron microscopy (HITACHI S$3000 \mathrm{~N}$ made in Germany) by placing the CAW and CAW Biochar samples on the aluminum holder using carbon tape whose image is scanned with an electron beam. Discharged electrons from the sample were gathered and rearranged at various amplifications to obtain the image of the sample.

\section{FTIR Analysis}

Spectra of all the CAW and CAW Biochar samples was captured using Fourier Transform Infrared Spectroscopy (Cary 630 FTIR with diamond ATR, Agilent Technologies, USA) which contains a detector, beam source, a ceramic source, and a beam splitter. The ATR sampling device applies a Dura Sample IR internal reflection accessory coated with diamond (Smiths Detection, Danbury, CT), and through the stainless steel rod, continuous pressure was employed along with an electronic load display.

\section{Kinetic methods}

Coats Redfern method ,Kissinger-Akahira-Sunose (KAS) and Ozawa-Flynn-Wall (OFW) methods (Ceylan and Topçu) were used to calculate reaction model $\mathrm{f}(\alpha)$, frequency factor $(\mathrm{A})$ and activation energy (E). Isoconversional methods are preferred by researches for two reasons (a) model-free kinetics are sufficiently flexible to allow for a change in mechanism during a reaction, and (b) mass loss transfer limitations are reduced by the use of multiple heating rates. 
Journal of Thermal Engineering, Research Article, Vol. 7, No. 2, Special Issue 13, pp. 18-29, February, 2021

\section{Method 1:}

Coats Redfern method:

In the pyrolysis reactor, the overall reaction mechanism of CAW is given by (Harrison)

$$
\text { Biomass }(\text { Solid })=\text { Volatile }(\text { Gases }+ \text { Tar })+\text { Char }(\text { Solid residue })
$$

In the present work, it was assumed that the conversion of CAW into CAW biochar is a single step process (Kumar et al.) and the rate of reaction $(\mathrm{K})$ is given by the following equation

$$
k=A e^{-\left(\frac{E}{R T}\right)}
$$

Where $A$ =pre-exponential factor, $\mathrm{k}=$ Reaction rate constant, $\mathrm{E}=$ Activation energy $\left(\mathrm{J} \mathrm{mol}^{-1} \mathrm{~K}^{-1}\right), \mathrm{R}=$ Gas constant $\left(8.314 \mathrm{~J} \mathrm{~mol}^{-1} \mathrm{~K}^{-1}\right)$ and $\mathrm{T}=$ Absolute temperature $(\mathrm{K})$.

The rate equation for modifying CAW to volatile state is given as

$$
\frac{\mathrm{d} \alpha}{\mathrm{dt}}=\mathrm{kf}(\alpha)
$$

Where

$$
\begin{aligned}
& \alpha=\text { rate of conversion } \\
& \mathrm{t}=\text { time }
\end{aligned}
$$

$\mathrm{f}(\alpha)$ is the reaction model

Conversion $(\alpha)$ is defined as

$$
\alpha=\frac{w_{0}-w_{t}}{w_{0}-w_{f}}
$$

Where

$$
\begin{aligned}
w_{0} & =\text { Initial weight of CAW } \\
w_{t} & =\text { Weight of CAW at a particular time } \\
w_{f} & =\text { Final weight of the CAW }
\end{aligned}
$$

By combining equations (3) and (4), we get

$$
\frac{\mathrm{d} \alpha}{\mathrm{dt}}=A e^{-\left(\frac{\mathrm{E}}{\mathrm{RT}}\right)} \mathrm{f}(\alpha)
$$

heating rate is defined as

$$
\begin{gathered}
\text { Heating rate, } \beta=\frac{d T}{d t}=\text { constant } \\
d t=\frac{d T}{\beta}
\end{gathered}
$$

Substituting dt from eq 7 in eq 5 and after integration, we get

$$
\begin{gathered}
\int_{0}^{\alpha} \frac{d \alpha}{f(\alpha)}=\int_{0}^{T} A \exp \left(\frac{-E}{R T}\right) \frac{d T}{\beta}=g(\alpha) \\
\frac{\mathrm{d} \alpha}{\mathrm{dt}}=\frac{\mathrm{A}}{\beta} \exp ^{\left(\frac{-\mathrm{E}}{\mathrm{RT}}\right)} \mathrm{f}(\alpha)
\end{gathered}
$$


Journal of Thermal Engineering, Research Article, Vol. 7, No. 2, Special Issue 13, pp. 18-29, February, 2021

Up on integration,

$$
\begin{array}{r}
g(\alpha)=\frac{\mathrm{A}}{\beta} \int_{0}^{\mathrm{T}} \exp ^{\left(\frac{\mathrm{E} a}{\mathrm{RT}}\right)} \mathrm{dT} \\
\mathrm{g}(\alpha)=\frac{\mathrm{AE}_{\mathrm{a}}}{\mathrm{RT}} \int_{\mathrm{x}}^{\infty} \frac{\exp (-\mathrm{x})}{\mathrm{x}^{2}} \mathrm{dx}=\frac{\mathrm{AE}_{\mathrm{a}}}{\mathrm{RT}} \mathrm{p}(\mathrm{x})
\end{array}
$$

Coats redfern method is the best approximation for the $\mathrm{p}(\mathrm{x})$ and utilizes the asymptotic series expansion for approximating the exponential integral in eq 11,giving

$$
\ln \left(\frac{g(\alpha)}{T^{2}}\right)=\ln \left(\frac{A R}{\beta E}\right)\left(1-\frac{2 R T}{E}-\frac{E}{R T}\right)
$$

Individual kinetic models symbolizing reaction between the phases, random nucleation, Nuclei growth, chemical reaction, and diffusion models are used to examine TGA data [3, 20, 25]. The data obtained from the TGA analysis during the pyrolysis of CAW stalk was analyzed using fourteen kinetic models (Table 1 ) using coats- Redfern equation. The reaction model best suited is the one which has the highest regression coefficient

\begin{tabular}{|c|c|c|c|}
\hline Model & Mechanism & $f(\alpha)$ & $g(\alpha)$ \\
\hline \multicolumn{4}{|c|}{ Chemical Reaction } \\
\hline 1 & First-order & $1-\alpha$ & {$[-\ln (1-\alpha)]$} \\
\hline 2 & Second-order & $(1-\alpha)^{2}$ & $(1-\alpha)^{-1}-1$ \\
\hline 3 & Third-order & $(1-\alpha)^{3}$ & {$\left[(1-\alpha)^{-2}-1\right] / 2$} \\
\hline 4 & $\mathrm{~N}^{\text {th }}$ order & $(1-\alpha)^{n}$ & {$\left[(1-\alpha)^{1-n}-1\right] / n-1$} \\
\hline \multicolumn{4}{|c|}{ Random nucleation and nuclei growth } \\
\hline 5 & $\begin{array}{c}\text { Two- } \\
\text { dimensional }\end{array}$ & $2(1-\alpha)[-\ln (1-\alpha)]^{1 / 2}$ & {$[-\ln (1-\alpha)]^{1 / 2}$} \\
\hline 6 & $\begin{array}{c}\text { Three- } \\
\text { dimensional }\end{array}$ & $3(1-\alpha)[-\ln (1-\alpha)]^{2 / 3}$ & {$[-\ln (1-\alpha)]^{1 / 3}$} \\
\hline \multicolumn{4}{|c|}{ Limiting surface reaction between both phases } \\
\hline 7 & One dimension & 1 & $\alpha$ \\
\hline 8 & $\begin{array}{c}\text { Two } \\
\text { dimensions }\end{array}$ & $2(1-\alpha)^{1 / 2}$ & $1-(1-\alpha)^{1 / 2}$ \\
\hline 9 & $\begin{array}{c}\text { Three } \\
\text { dimensions }\end{array}$ & $3(1-\alpha)^{2 / 3}$ & $1-(1-\alpha)^{1 / 3}$ \\
\hline \multicolumn{4}{|c|}{ Diffusion } \\
\hline 10 & $\begin{array}{l}\text { One way } \\
\text { transport }\end{array}$ & $1 / 2 \alpha$ & $\alpha^{2}$ \\
\hline 11 & $\begin{array}{l}\text { Two-way } \\
\text { transport }\end{array}$ & {$[-\ln (1-\alpha)]^{-1}$} & $\alpha+(1-\alpha) \ln (1-\alpha)$ \\
\hline 12 & $\begin{array}{l}\text { Three-way } \\
\text { transport }\end{array}$ & $(2 / 3)(1-\alpha)^{2 / 3} /\left[1-(1-\alpha)^{1 / 3}\right]$ & {$\left[1-(1-\alpha)^{1 / 3}\right]^{2}$} \\
\hline 13 & $\begin{array}{l}\text { Ginstling- } \\
\text { Brounshtein } \\
\text { equation }\end{array}$ & $(2 / 3)(1-\alpha)^{1 / 3} /\left[1-(1-\alpha)^{1 / 3}\right]$ & $1-2 \alpha / 3-(1-\alpha)^{2 / 3}$ \\
\hline 14 & $\begin{array}{c}\text { Zhuravlev } \\
\text { equation }\end{array}$ & $(2 / 3)(1-\alpha)^{5 / 3} /\left[1-(1-\alpha)^{1 / 3}\right]$ & {$\left[(1-\alpha)^{\wedge}((-1) / 3)-1\right]^{2}$} \\
\hline
\end{tabular}
for the graph between $\ln \left(g(\alpha) / T^{2}\right)$ versus $1 / \mathrm{T}$.

Table 1: Various kinetic models for solid-state reactions 
Method 2:

Kissinger-Akahira-Sunose (KAS) method: The kinetic energy of the CAW stalk can be calculated by using the model-free iso-conversion method named Kissinger-Akahira-Sunose (KAS).

$$
\begin{gathered}
\frac{E}{R T}=C \\
d C=\frac{-E}{R} T^{-2} d T \\
\text { As } T \rightarrow 0 ; C \rightarrow \infty \text { and } T \rightarrow T ; C \rightarrow C
\end{gathered}
$$

On rearrangement eq 9 is transformed to

$$
\ln \frac{\beta}{T^{2}}=\ln \frac{A R}{E g(\alpha)}-\frac{E}{R T}
$$

Thus a plot of $\ln \frac{\beta}{T^{2}} \frac{1}{T}$ vs gives Activation energy and pre-exponential factor values.

\section{Method 3:}

The Flynn-Wall-Ozawa (FWO) Method: This is one of the integral methods that can determine the activation energy which does not require the knowledge of reaction order.

Ozawa Flynn wall method is based on Doyle's approximation for eq 9

$$
\log (\beta)=\log \left[\frac{(A E)}{R g(\alpha)}\right]-2.315-0.457 \frac{E}{R T}
$$

Thus a plot of $\ln \beta \frac{1}{T}$ vs gives activation energy and pre-exponential factor values.

Enthalpy $(\Delta \mathrm{H})$ values are calculated using Flynn-Wall-Ozawa (FWO) method by using the following equation

$$
\Delta H=E-R T
$$

\section{RESULTS AND DISCUSSION}

\section{Proximate and ultimate analysis}

Pyrolysis of CAW was performed using the TG-DTG analyzer and the product CAW Biochar was obtained at $1173 \mathrm{~K}$. Proximate and ultimate analysis was done for CAW and CAW Biochar obtained through pyrolysis and the results were tabulated in Table 2 .

From Table 2 it was clear that CAW has $3 \%$ moisture ensuring to be the best feedstock for the pyrolysis process moreover it has a volatile matter of $80.23 \%$ and less ash content of $0.82 \%$ indicating higher ignition of the fuel. Ultimate analysis of CAW confirmed the higher amounts of carbon $(40.53 \%)$ illustrating the feasibility of CAW as fuel and energy production. The release of S-N compounds all along the pyrolysis of CAW will be limited due to the existence of reduced amounts of nitrogen and sulfur. 
Journal of Thermal Engineering, Research Article, Vol. 7, No. 2, Special Issue 13, pp. 18-29, February, 2021

Table 2: Proximate and Ultimate analysis of CAW and CAW Biochar

\begin{tabular}{|l|l|l|}
\hline Component & CAW & $\begin{array}{l}\text { CAW Biochar } \\
\text { 10 K min }\end{array}$ \\
\hline \multicolumn{2}{|l|}{ Ultimate Analysis (wt. \%) } \\
\hline C & 40.53 & 78.6 \\
\hline H & 5.02 & 2.67 \\
\hline N & 0.77 & 1.29 \\
\hline S & 0.14 & 0.41 \\
\hline O & 53.54 & 17.03 \\
\hline Proximate Analysis (wt. \%) & \multicolumn{2}{|l|}{} \\
\hline Ash & 0.82 & 12.12 \\
\hline Volatile Matter & 80.23 & 25.32 \\
\hline Fixed carbon & 18.95 & 62.56 \\
\hline Moisture & 3 & - \\
\hline Other Properties & \multicolumn{2}{|l}{} \\
\hline H/C & 0.123 & 0.033 \\
\hline C/O & 0.757 & 4.615 \\
\hline
\end{tabular}

\section{TG/DTG and DSC Analysis}

The results of Wt Loss of the sample was reported against time (Figure 1). Heat disintegration behavior of CAW was studied at 10, 20 and $30 \mathrm{~K} \mathrm{~min}^{-1}$ heating rates. During the pyrolysis of CAW, initially, dehydration occurs for about 10 minutes up to $523 \mathrm{~K}$ where moisture and volatile matter were taken off thereby decomposition of cellulose, hemicellulose and lignin content takes place. The vigorous mass loss appears within 473 to $673 \mathrm{~K}$ from 10 to 20 minutes where cellulose and hemicellulose decompose.

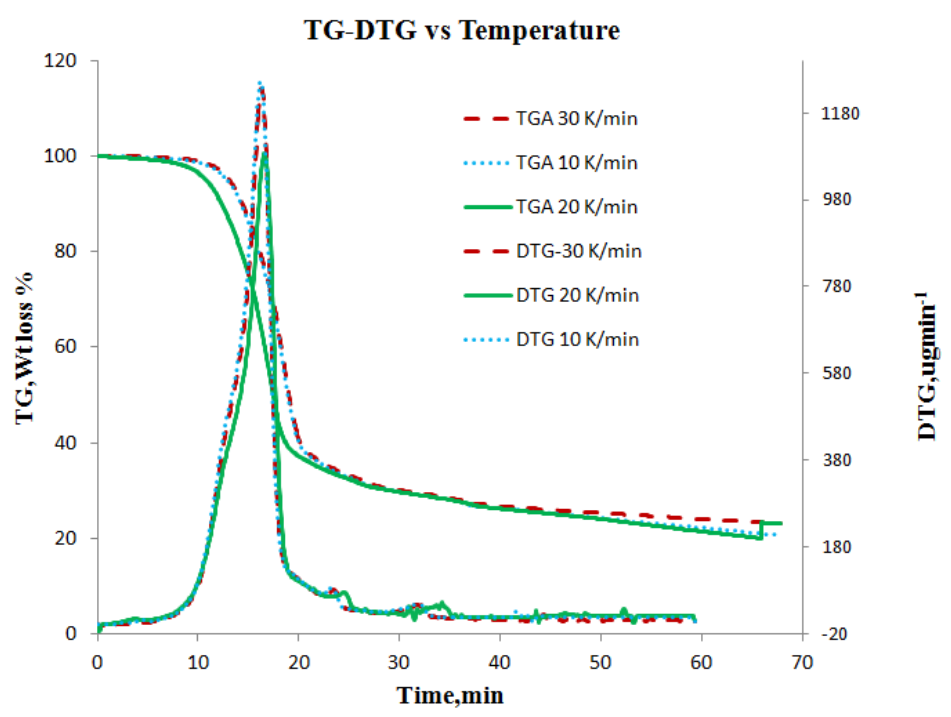

Figure 1. Thermogram of CAW at 10,20 and $30 \mathrm{~K} \mathrm{~min}^{-1}$ heating rates

During 473 to $673 \mathrm{~K}$ of primary pyrolysis stage the aromatic compounds decomposed are only 2 -methoxy phenols and 2,6 -dimethoxy phenols since aromatic methoxy groups are stable during this stage . But when the pyrolysis temperature increased above $673 \mathrm{~K}$, secondary pyrolysis reactions takes place and guaiacols/syringols rapidly transition to catechols or pyrogallols and $\mathrm{O}$ - cresols along with phenols. Lignin content may not be completely degraded at $1173 \mathrm{~K}$. Similar trend was observed for all the heating rates employed. 


\section{Differential Scanning Calorimetric analysis:}

Heat flow property of the CAW was studied using Differential Scanning Calorimetric analysis at individual heating rates of 10, 20 and $30 \mathrm{~K} \mathrm{~min}^{-1}$ (Figure 2). DSC curve depicts that the reaction pathway of $\mathrm{CAW}$ went from endothermic to the exothermic stage and also the appearance of the first peak below $373 \mathrm{~K}$ indicates endothermic evaporation of water molecules.

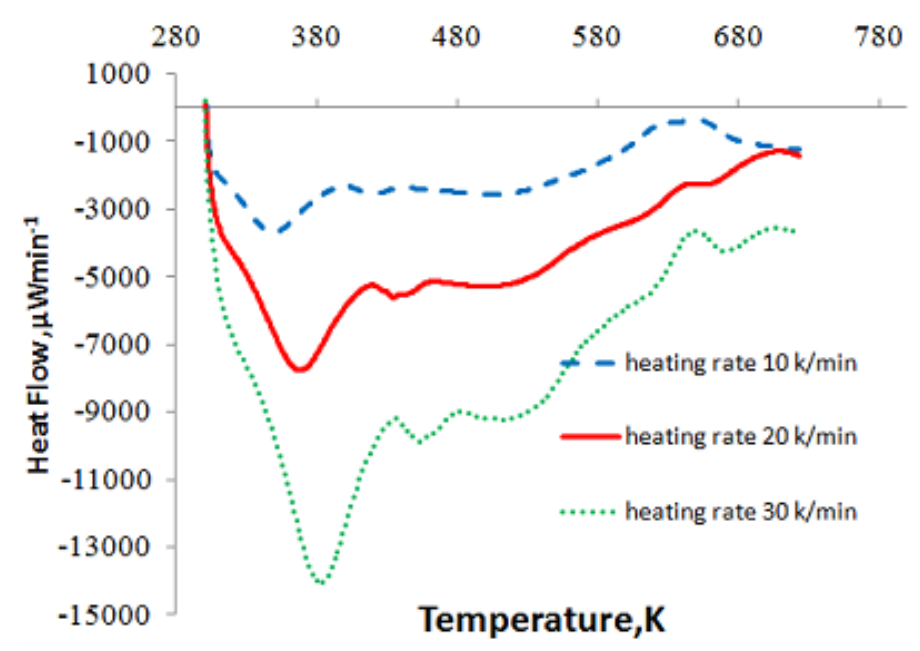

Figure 2: DSC analysis of CAW at heating rates of 10, 20 and $30 \mathrm{~K}$ min-1

The peaks observed above $423 \mathrm{~K}$ indicates decomposition of cellulose and hemicellulose compounds and a comparable trend was marked in the previous works [25].

\section{Scanning Electron Microscope Analysis}

The surface morphology changes from CAW to CAW Biochar were analyzed using a scanning electron microscope (SEM) and are presented in Figure 3 for CAW and CAW Biochar obtained through pyrolysis. It was observed that a good number of pore volumes are available in the case of CAW Biochar as compared to that of CAW resembling high surface areas for carbofuran adsorption.

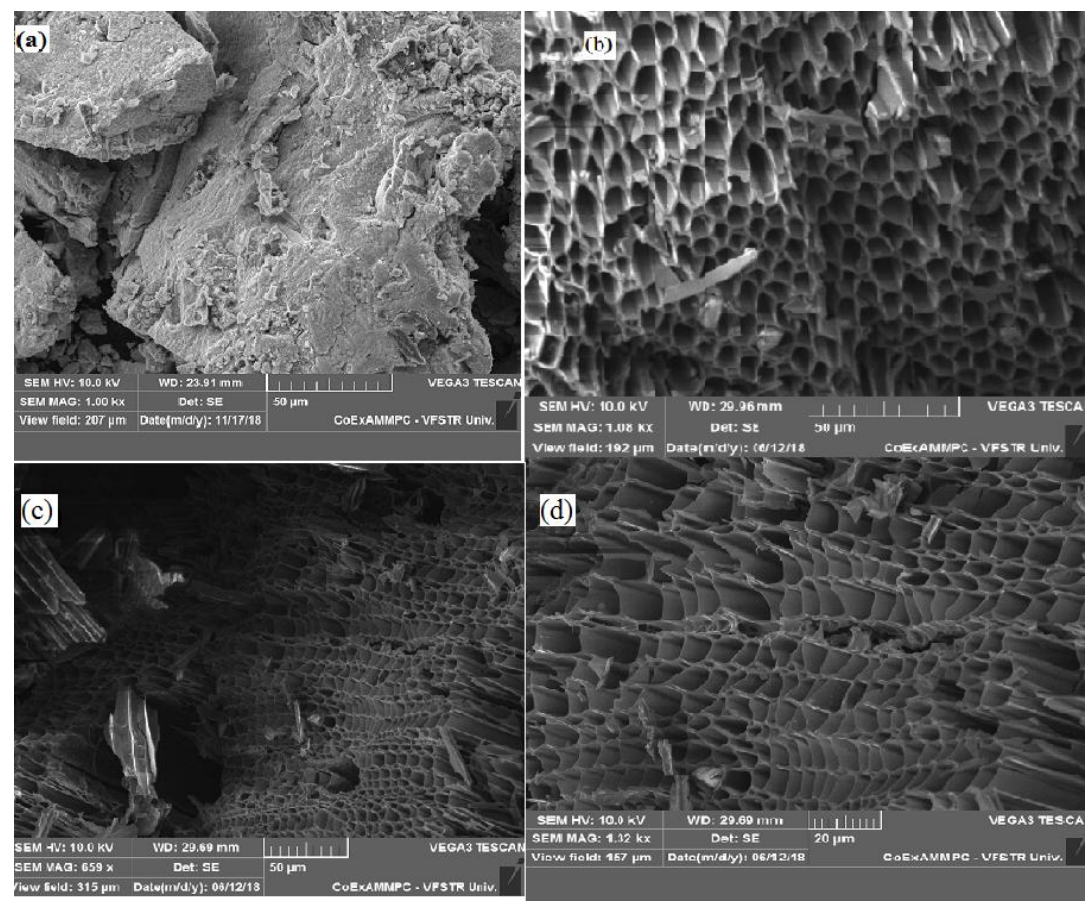

Figure 3: Surface morphology images of (a) CAW (b) CAW Biochar $\left(300^{\circ} \mathrm{C}\right)(\mathrm{c})$ CAW Biochar $\left(700^{\circ}\right)$ (d)Carbofuran adsorbed biochar 


\section{FTIR analysis}

FTIR analyses of the raw CAW and CAW Biochar have been investigated to identify the variation in the functional groups through spectral changes, which is displayed in Figure 4.

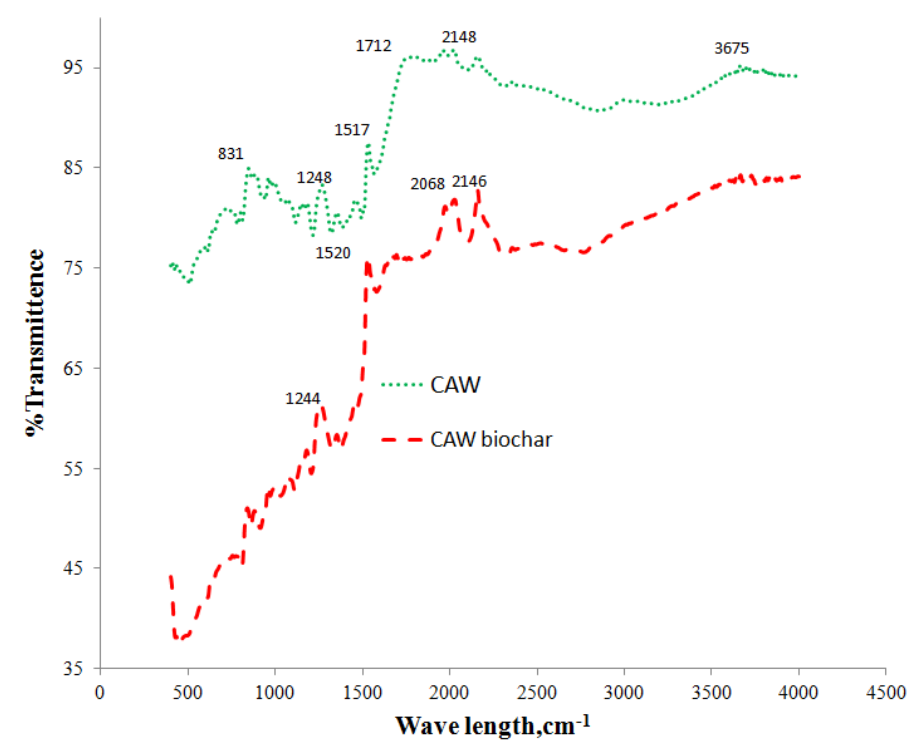

Figure 4: FTIR spectrum of (a) CAW (b) CAW Biochar

In CAW, the wavenumber observed between $800-1000 \mathrm{~cm}^{-1}$ indicates the medium C-O stretching vibration of carboxyl groups in the cell wall and there is a sudden drop in the transmittance from 87.04 to 82.86 $\mathrm{cm}^{-1}$ which represents the strong C-H bending. A peak around $1200 \mathrm{~cm}^{-1}$ indicates the presence of symmetrical stretch nitro compounds. The peaks close to $1500 \mathrm{~cm}^{-1}$ are accredited to $\mathrm{C}=\mathrm{C}$ stretching vibration of aromatic rings [14]. A peak at $1200 \mathrm{~cm}^{-1}$ signifies the presence of aliphatic C-O-C and secondary alcohol, C-O stretch at around $1000 \mathrm{~cm}^{-1}$ group indicate the presence of hemicelluloses and cellulose in CAW and CAW Biochar. Broad peaks observed between $3500-3800 \mathrm{~cm}^{-1}$ for CAW decreased in the case of CAW Biochar, which indicates the desiccation of cellulose and ligneous constituents.

\section{Kinetic parameter estimation:}

Pyrolysis of CAW involves both heat and mass transfer phenomenon and the obtained data were analyzed using fourteen distinctive models (Table 1). From the results third -order reaction model with $(\alpha)=(1-\alpha)^{\wedge} 3$ was observed to be the best correlation at three individual heating rates of $10,20,30 \mathrm{~K} \mathrm{~min}^{-1}$ (Figure 5 ).

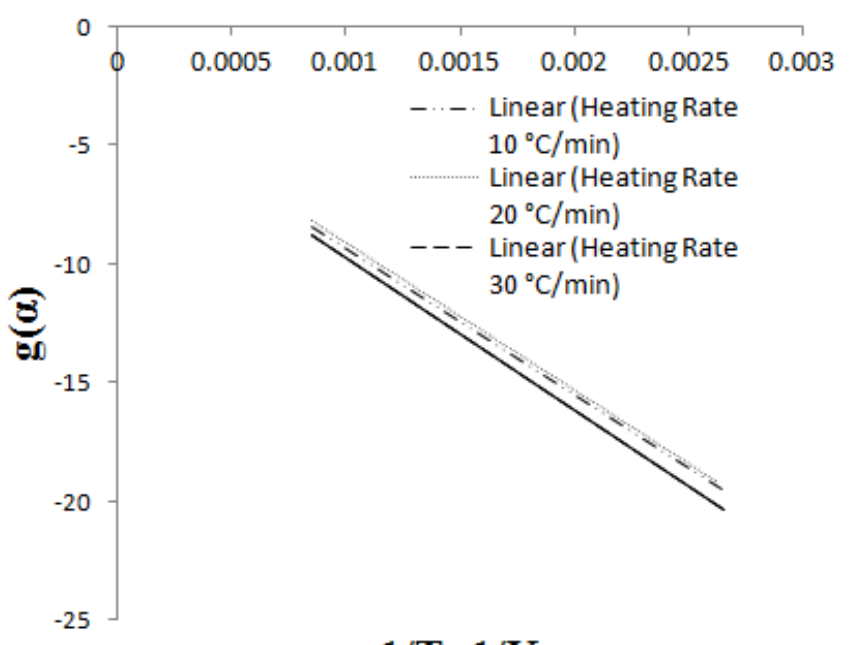

1/T, $1 / \mathrm{K}$

Figure 5: Coats Redfern method- Third-order reaction model 
Kinetic triplet for CAW pyrolysis reaction from the Coats-Redfern method was given in Table: 3 . Activation energy values are found to be $51.26,51.63$ and $53.60 \mathrm{KJ} / \mathrm{mol}$ and frequency factor values are found to be 2650,7070 and $7480 \mathrm{~min}^{-1}$ at three heating rates of 10,20 and $30 \mathrm{~K} \mathrm{~min}^{-1}$ respectively. Both the kinetic parameters, Activation energy, and frequency factor were increased with heating rate and the same trend is observed in the literature [15].

Table 3: Kinetic triplet for CAW pyrolysis using coats -Redfern method

\begin{tabular}{|c|c|c|c|c|}
\hline $\begin{array}{c}\text { Heating } \\
\text { rate, } \\
\mathbf{K ~}_{\text { }} \mathbf{1 n}^{-\mathbf{1}}\end{array}$ & $\begin{array}{c}\text { Reaction } \\
\text { model, } \\
\boldsymbol{f}(\boldsymbol{\alpha})\end{array}$ & $\begin{array}{c}\text { Activation energy, } \\
\boldsymbol{E}, \mathbf{K J ~ m o l}^{\mathbf{1}}\end{array}$ & $\begin{array}{c}\text { Frequency } \\
\text { factor, } \\
\boldsymbol{A}, \mathbf{m i n}^{-1}\end{array}$ & $\begin{array}{c}\text { Correlation } \\
\text { coefficient, } \\
\boldsymbol{R}^{\mathbf{2}}\end{array}$ \\
\hline 10 & $(1-\alpha)^{3}$ & 51.26 & $2.65 \times 10^{3}$ & 0.9639 \\
\hline 20 & $(1-\alpha)^{3}$ & 51.63 & $7.07 \times 10^{3}$ & 0.9511 \\
\hline 30 & $(1-\alpha)^{3}$ & 53.60 & $7.48 \times 10^{3}$ & 0.9465 \\
\hline
\end{tabular}

The obtained TGA data were also analyzed using iso-conversion methods such as Kissinger-AkahiraSunose (KAS) method and Flynn-Wall-Ozawa (FWO) method and the regression lines for different conversion values at three individual heating rates of $10,20,30 \mathrm{~K} \mathrm{~min}^{-1}$ are displayed in Figure $6 \mathrm{a}$ and $6 \mathrm{~b}$ respectively. Activation energy and regression coefficient values obtained by both the methods are presented in table 4 . Activation energy values from the KAS method range from 32.49 to $15.28 \mathrm{KJ} / \mathrm{mol}$ as the conversion values vary from 0.1 to 0.9 and that of Flynn-Wall-Ozawa (FWO) method varies from 69.76 to $45.07 \mathrm{KJ} / \mathrm{mol}$. Enthalpy $(\Delta \mathrm{H})$ values are calculated using Flynn-Wall-Ozawa (FWO) method. Since there is a small difference between activation energies of the CAW at different conversion percentages, less amount of energy is sufficient for the thermal conversion of this CAW [18].

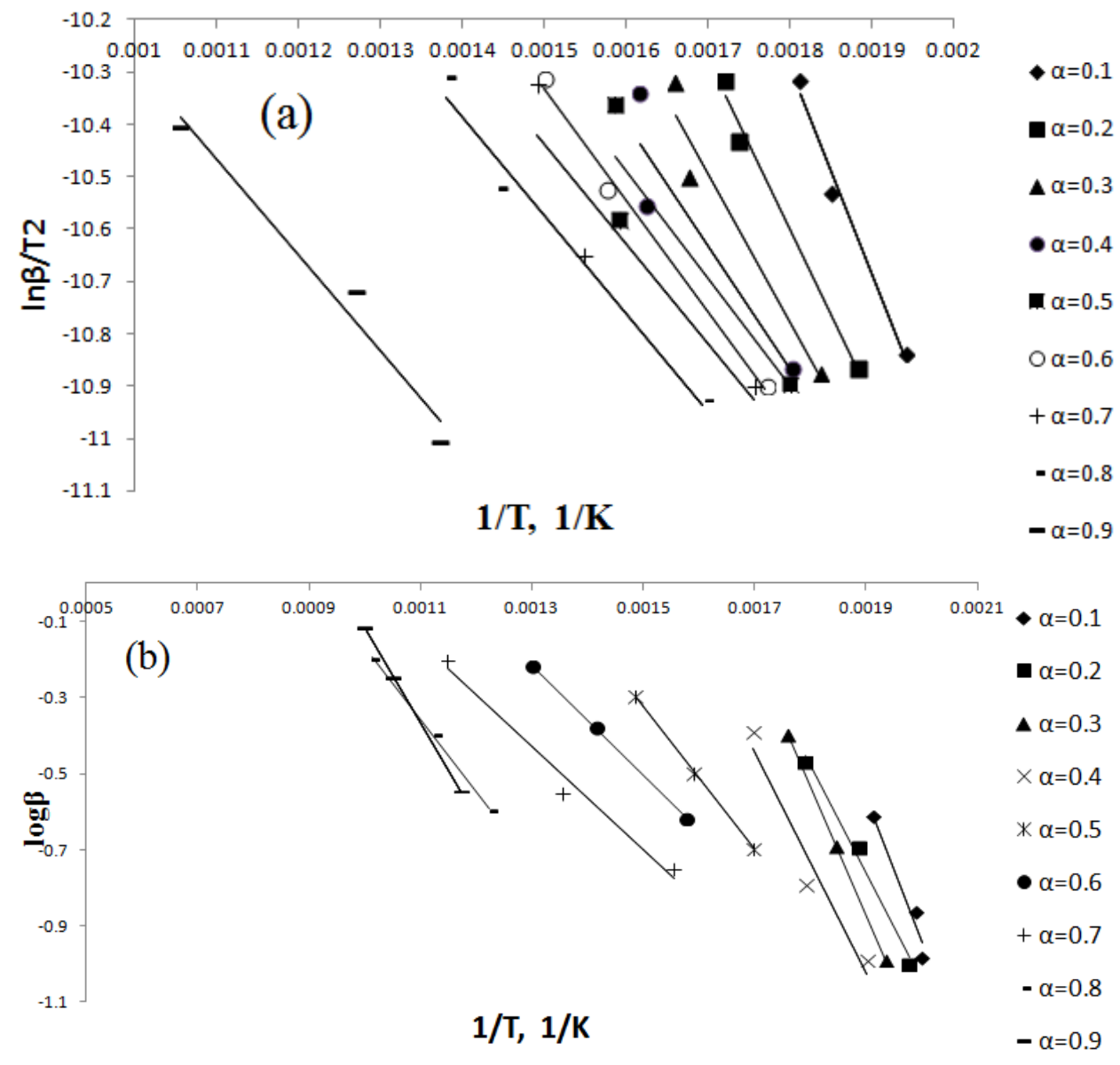

Figure 6: (a) Kissinger-Akahira-Sunose (KAS) method and (b) Flynn-Wall-Ozawa 
Journal of Thermal Engineering, Research Article, Vol. 7, No. 2, Special Issue 13, pp. 18-29, February, 2021

Table 4: Arrhenius parameters and regression values from KAS and OFW methods

\begin{tabular}{|c|c|c|c|c|c|}
\hline \multirow{2}{*}{$\begin{array}{c}\text { Conversion } \\
\alpha\end{array}$} & \multicolumn{2}{|c|}{ KAS method } & \multicolumn{3}{c|}{ OFW method } \\
\cline { 2 - 6 } & E, KJ/mol & $\mathrm{R}^{2}$ & E, KJ/mol & $\mathrm{R}^{2}$ & $\Delta$ H, KJ/mol \\
\hline 0.1 & 32.49 & 0.9836 & 69.76 & 0.9519 & 65.1678 \\
0.2 & 26.89 & 0.9891 & 51.19 & 0.9886 & 46.3629 \\
0.3 & 23.46 & 0.9424 & 61.04 & 0.9999 & 56.0348 \\
0.4 & 19.32 & 0.8599 & 52.40 & 0.9468 & 47.2570 \\
0.5 & 17.61 & 0.8511 & 33.86 & 0.9999 & 28.6160 \\
0.6 & 16.90 & 0.9927 & 26.16 & 0.9997 & 20.8314 \\
0.7 & 15.75 & 0.8453 & 24.66 & 0.9778 & 19.2242 \\
0.8 & 15.48 & 0.9761 & 34.39 & 0.999 & 28.5156 \\
0.9 & 15.28 & 0.9714 & 45.07 & 0.9998 & 37.2007 \\
\hline
\end{tabular}

There is a decreasing trend in the activation energies using KAS method but in OFW method even though there is a small discrepancy in the decreasing trend, the activation energy decreased from 69.76 to 45.07 when the conversion increases from 0.1 to 0.9 . With increasing conversions since at high temperatures, high conversions are attained and there is a need for fewer activation energies at these high temperatures. For largescale design and operation of pyrolysis processes, the kinetic parameter values obtained from these model-free methods are favorable and these values tie technical parameters at predefined conditions, which in turn give the complete picture of the pyrolysis products.

\section{CONCLUSION}

This article is the first of its kind to study the thermogravimetric analysis for CAW at 10,20 and $30 \mathrm{~K}$ $\min ^{-1}$ heating rates under inert $\mathrm{N}_{2}$ atmosphere to examine the solid-state reaction kinetics of CAW pyrolysis and kinetic parameters. The methods Kissinger-Akahira-Sunose (KAS), Flynn-Wall-Ozawa (FWO) and CoatsRedfern were used and the experimental information acquired was well correlated for CAW pyrolysis reaction with third-order reaction model. Characteristic studies also depict that the CAW biochar has the number of pores that can have more applications as a soil conditioner, biosorbent, etc. Activation energy from Coats Redfern method was found to be $51.26,51.63$ and $53.60 \mathrm{~kJ} \mathrm{~mol}^{-1}$ and Arrhenius frequency factor was found to be 2650, 7070 and $7480 \mathrm{~min}^{-1}$ at three heating rates of 10,20 and $30 \mathrm{~K} \mathrm{~min}^{-1}$ respectively. Average values of activation energies computed from KAS and OFW were found to be 20.35 and $44.28 \mathrm{~kJ} \mathrm{~mol}^{-1}$ respectively. The obtained kinetic report can be useful to the design and development of pyrolyzers. From the present study, it was also clear that CAW can be effectively used for energy generation.

\section{REFERENCES:}

[1] Abbasi, Tasneem, and S. A. Abbasi. Biomass Energy and the Environmental Impacts Associated with Its Production and Utilization. Vol. 14, 2010, pp. 919-37, doi:10.1016/j.rser.2009.11.006.

[2] Bhavanam, Anjireddy, and R. C. C. Sastry. "Kinetic Study of Solid Waste Pyrolysis Using Distributed Activation Energy Model.” Bioresource Technology, vol. 178, Elsevier Ltd, Feb. 2015, pp. 126-31, doi:10.1016/j.biortech.2014.10.028.

[3] Ceylan, Selim, and Yıldıray Topçu. "Bioresource Technology Pyrolysis Kinetics of Hazelnut Husk Using Thermogravimetric Analysis." BIORESOURCE TECHNOLOGY, vol. 156, Elsevier Ltd, 2014, pp. 182-88, doi:10.1016/j.biortech.2014.01.040. 
[4] Collins, Stephen, and Praveen Ghodke. "Kinetic Parameter Evaluation of Groundnut Shell Pyrolysis through Use of Thermogravimetric Analysis." Journal of Environmental Chemical Engineering, vol. 6, no. 4, Elsevier, 2018, pp. 4736-42, doi:10.1016/j.jece.2018.07.012.

[5] F.J.A. Antunes, and J. L. Figueiredo. Pyrolysis Kinetics of Lignocellulosic MaterialsĐthree Independent Reactions Model. Vol. 78, 1999.

[6] Ponnam V, Katari NK, Mandapati RN, Nannapaneni S, Tondepu S, Jonnalagadda SB. Efficacy of biochar in removal of organic pesticide, Bentazone from watershed systems. J Environ Sci Health B. 2020;55(4):396-405. doi: 10.1080/03601234.2019.1707008. Epub 2020 Jan 6. PMID: 31905102..

[7] Ghodke, Praveen, and Ramesh Naidu Mandapati. "Investigation of Particle Level Kinetic Modeling for Babul Wood Pyrolysis.” Fuel, vol. 236, no. July 2018, Elsevier, 2019, pp. 1008-17, doi:10.1016/j.fuel.2018.09.084.

[8] Ponnam, V., Reddy, R.A., Sumalatha, BSorption and Desorption Studies for the Removal of Bentazone using Biochar Amended Soil, Indian Journal of Ecology, 47(11), 128-131, 2020

[9] Harrison, L. G. "The Theory of Solid Phase Kinetics." Comprehensive Chemical Kinetics, vol. 2, no. C, 1969, pp. 377-462, doi:10.1016/B978-0-444-40674-3.50011-0.

[10] Johnson, R. L., et al. Abundant and Stable Char Residues in Soils: Implications for Soil Fertility and Carbon Sequestration. 2012.

[11] Jong, W. De, et al. Pyrolysis of Miscanthus Giganteus and Wood Pellets : TG-FTIR Analysis and Reaction Kinetics Q. Vol. 82, 2003, pp. 1139-47, doi:10.1016/S0016-2361(02)00419-2.

[12] Kumar, Anup, et al. "Bioresource Technology Modelling of Pyrolysis of Large Wood Particles." Bioresource Technology, vol. 100, no. 12, Elsevier Ltd, 2009, pp. 3134-39, doi:10.1016/j.biortech.2009.01.007.

[13] L.K.Velayutham, 1Dr., and 2Dr. K. Damodaran. Growth Rate of Chilli Production in Guntur District of Andhra Pradesh. Vol. 2, no. 11, 2015, pp. 1-5.

[14] Mishra, Ranjeet Kumar, and Kaustubha Mohanty. "Pyrolysis Kinetics and Thermal Behavior of Waste Sawdust Biomass Using Thermogravimetric Analysis Ranjeet Kumar Mishra , Kaustubha Mohanty." Bioresource Technology, Elsevier Ltd, 2017, doi:10.1016/j.biortech.2017.12.029.

[15] Muktham, Radhakumari, et al. Study of Thermal Behavior of Deoiled Karanja Seed Cake Biomass : Thermogravimetric Analysis and Pyrolysis Kinetics. 2016, doi:10.1002/ese3.109.

[16]Parthasarathy, Prakash, and Sheeba K. Narayanan. Determination of Kinetic Parameters of Biomass Samples Using Thermogravimetric Analysis. Vol. 00, no. 00, 2013, doi:10.1002/ep.

[17] Pode, Ramchandra. "Potential Applications of Rice Husk Ash Waste from Rice Husk Biomass Power Plant." Renewable and Sustainable Energy Reviews, vol. 53, Jan. 2016, pp. 1468-85, doi:10.1016/j.rser.2015.09.051.

[18] Ren, Liang, et al. Preparation and Evaluation of Cattail Fiber-Based Activated Carbon For. Vol. 168, 2011, pp. 553-61, doi:10.1016/j.cej.2011.01.021.

[19] Sarkar, Arunabha, and Ghodke Praveen. "Utilization of Waste Biomass into Useful Forms of Energy." Springer Proceeding in Energy, 2017, pp. 117-32, doi:10.1007/978-3-319-47257-7_12.

[20] Shawalliah, Siti, et al. "Bioresource Technology Combustion Characteristics of Malaysian Oil Palm 
Biomass, Sub-Bituminous Coal and Their Respective Blends via Thermogravimetric Analysis ( TGA ).” Bioresource Technology, vol. 123, no. 2012, Elsevier Ltd, 2020, pp. 581-91, doi:10.1016/j.biortech.2012.07.065.

[21] Silva, Rita Barros, et al. "Pyrolysis and Char Characterization of Refuse-Derived Fuel Components." Energy \& Fuels, vol. 29, no. 3, American Chemical Society, Mar. 2015, pp. 1997-2005, doi:10.1021/ef502011f.

[22] Song, X. D., et al. Chemosphere Application of Biochar from Sewage Sludge to Plant Cultivation : Influence of Pyrolysis Temperature and Biochar-to-Soil Ratio on Yield and Heavy Metal Accumulation. 2014, doi:10.1016/j.chemosphere.2014.01.070.

[23] Tinwala, Farha, et al. "Intermediate Pyrolysis of Agro-Industrial Biomasses in Bench-Scale Pyrolyser: Product Yields and Its Characterization.” Bioresource Technology, vol. 188, Elsevier Ltd, 2015, pp. 258-64, doi:10.1016/j.biortech.2015.02.006.

[24] Vijetha Ponnam 1 , Subbaiah Tondepu 1, Vineet Aniya 2, Alka Kumari 2 , Satyavathi Bankupalli 2,*, Ramesh Naidu Mandapati 1. Torrefied and Unmodified Capsicum Annuam Biochar for the Removal of Synthetic Hazardous Pesticide (Carbofuran) from Watershed. Vol. 9, no. 5, 2019, pp. 4384-93.

[25] Vlaev, L. T., et al. Non-Isothermal Kinetics of Pyrolysis of Rice Husk. Vol. 406, no. January, 2003, pp. 1-7, doi:10.1016/S0040-6031(03)00222-3.

[26] Vyazovkin, Sergey, and Charles A. Wight. Model-Free and Model- ® Tting Approaches to Kinetic Analysis of Isothermal and Nonisothermal Data. Vol. 341, 1999, pp. 53-68.

[27] Wang, Xue-li, et al. "Study on the Solubilization Capacity of Bio-Oil in Diesel by Microemulsion Technology with Span80 as Surfactant.” Fuel Processing Technology, vol. 118, Feb. 2014, pp. 141-47, doi:10.1016/j.fuproc.2013.08.020.

[28] Yangali, Pablo, et al. "Co-Pyrolysis Reaction Rates and Activation Energies of West Virginia Coal and Cherry Pit Blends.” Journal of Analytical and Applied Pyrolysis, vol. 108, July 2014, pp. 203-11, doi:10.1016/j.jaap.2014.04.015. 